\title{
The use of Differential Scanning Fluorimetry in the Rational Design of Plastic Antibodies for Protein Targets
}

\author{
Jon Ashley ${ }^{\mathrm{a}}$ Yunus Shukor ${ }^{\mathrm{b}}$ and Ibtisam E. Tothill ${ }^{\mathrm{a}^{*}}$ \\ ${ }^{a}$ Cranfield University, College Road, Cranfield, Bedfordshire MK43 0AL, England, UK \\ ${ }^{b}$ Dept. of Biochemistry, Faculty of Biotechnology and Biomolecular Sciences, Universiti Putra Malaysia, 43400 \\ UPM Serdang, Selangor, Malaysia. \\ Corresponding Author; i.tothill@.cranfield.ac.uk
}

\begin{abstract}
The Development of moelcularly imprinted polymer nanoparticles (MIP-NPs), which specfically bind biomolecules, is of great interest in the area of biosensors, sample purification, therapeutic agents and biotechnology. Polymerisation techniques such as precipitation polymerisation, solid phase synthesis and core shell surface imprinting have allowed for significant improvements to be made in developing MIP-NPs which specifically recognise proteins. However, the development of MIP-NPs for protein templates (targets) still require lengthy optimisation and characterisation using different ratios of monomers in order to control their size, binding affinity and specificity. In this work we succesfully demonstrated that differential scanning fluorimtery (DSF) can be used to rapidly determine the optimum imprinting conditions and monomer composition required for MIP-NP design and polymerisation. This is based on the stability of the protein template and shift in apparent melting points (Tm) upon interaction with different functional acrylic monomers. The method allows for the characterisation of molecularly imprinted nanoparticles (MIP-NPs) due to the observed differences in melting point profiled between, protien -MIP-NPs complexes, prepolymerisation mixtures and non -imptrinted nanoparticles (NIP-NPs) without the need for prior purification. The technique is simple, rapid and can be carried out on most quantitative polymerase chain reaction (qPCR) thermal cyclers which have the required filters for SYPROC orange and could lead to the rapid development of MIPs nanoparticles for proteins.
\end{abstract}

KEYWORDS: Nanoparticles, Molecularly imprinted polymers, Differential scanning fluorimetry, Self-assembly, Proteins. 


\section{Introduction}

Molecularly imprinted polymers (MIPs) are synthetic based receptors which can recognise and bind to a large number of molecules. They are an attractive alternative to natural antibodies demonstrating comparable binding affinities and specificity towards their targets as well as some in vivo activity ${ }^{1,2}$. MIPs show greater stability, are relatively cheap to synthesise when compared to natural antibodies and have been demonstrated in a number of different applications including biosensing, biomedical and pharmaceutical applications ${ }^{3}$.

Although progress has been made in imprinting small molecule templates, imprinting MIPs for biological macromolecules remain a challenge. Macro biomolecules are incompatible with organic solvents and require polymerisation to be carried out in aqueous solutions ${ }^{4-7}$. In order to overcome some of these issues, several publications have reported on the synthesis of molecularly imprinted polymer nanoparticles (MIP-NPs) or plastic antibodies from solution based precipitation polymerisation ${ }^{8}$. MIP-NPs for a number of proteins and small peptides such as IgG, lysozyme and tryptophan have shown good binding affinities, selectivity and typically have hydrodynamic diameters of between $50-200 \mathrm{~nm}^{9,10}$. This method can be carried out in aqueous solution as well as allowing more facile template removal by incorporating thermally responsive monomers into the structure of the MIP-NPs.

The synthesis of core-shell based nanoparticles for proteins where imprinting is carried out on the surface of the nanoparticle has also been reported in the literature allowing for multiple binding sites to be formed as well as utilising the properties of the encapsulated nanoparticles ${ }^{11-}$ 13. More recently, solid phase based methods for the synthesis of MIP-NPs have been demonstrated using biological macromolecules immobilised onto glass beads ${ }^{14-17}$. This method also helps to prevent encapsulation of the protein and allows for the effective elution of high affinity MIP-NPs without further purification. In addition, the orientation of the template can be fixed resulting in the synthesis of a more uniform MIP-NP with the same active binding site $^{18}$.

The current described methods for developing protein MIP-NPs often require lengthy optimisation involving the screening of a number of reaction parameters such as the type and concentration of acrylic monomer used, concentrations of the initiator and catalyst ammonium persulphate (APS) and N,N,N',N'-tetramethylethylene-1,2- diamine (TEMED), as well as reaction times and polymerisation temperatures. The success of polymerization can then only be accessed after purification by measuring the binding affinity and selectivity of the MIP-NPs 
using an appropriate analytical technique such as quartz crystal microbalance (QCM), surface plasmon resonance (SPR) sensors or SDS-PAGE ${ }^{19,20}$. Computational studies have allowed for the effective design of MIP-NPs but are currently limited to small targets such as drugs, toxins and other small molecules due to the complexity of modelling biological macromolecules and their interactions ${ }^{21-24}$. Attempts to simulate protein imprinting have been performed by Levi et al to assess the pore properties, efficiency and selectivity of imprinting ${ }^{25-27}$.

Differential scanning fluorimetry (DSF) is a technique used to measure thermal stability of a proteins in a given set of conditions such as $\mathrm{pH}$, ionic buffer strength and salt concentrations ${ }^{28}$. The technique also allows for the measurement of increased melting points of protein upon binding to small ligands. A typical assay involves plotting florescence signal against incremental increases in temperature. The fluorescence is measured by using SYPRO ${ }^{\circledR}$ orange dye, protein stain which binds non-specifically to the hydrophobic regions of a protein causing a fluorescence signal which is quenched in water allowing for the apparent unfolding of the protein to be assessed ${ }^{29,30}$. SYPRO ${ }^{\circledR}$ orange shows relatively little background fluorescence signal in protein polyacrylamide gels. Experiments can typically be carried out on a 96 well plate real time-PCR machine meaning that a large number of different protein buffer conditions and ligand interactions can be screened at the same time. The technique has been used in several areas of research including drug discovery, protein crystallography and protein engineering ${ }^{31-}$ 33.

In this paper, we report on the first use of differential scanning fluorimetry in the rapid characterisation and optimisation of protein MIP-NPs in situ, with a general scheme of work is shown in Scheme 1. The technique allows for high throughput screening of different acrylic acid monomer mixtures and buffer conditions in the presence of the protein template as an alternative to molecular modelling and trial and error based approaches to assess the degree of self-assembly of monomers towards the protein template. The technique also allows for the direct characterisation of MIP-NP synthesis reducing the time to analyse one batch and can complement present techniques. To the best of our knowledge, this is the first known example of DSF being used for direct characterisation of the protein- MIP-NP complex formation and screening of monomer: protein self-assembly in pre-polymerisation mixtures. The technique can also be used to determine the conditions needed to prevent MIP aggregation and protein denaturing, a significant problem in the production of MIP-NPs. In this study, $\beta$-lactoglobulin (BLG) was selected as the model protein template ${ }^{34,35}$. There are currently no previous reports 
on the synthesis of MIP-NPs against BLG. However, Turner et al, reported on the use of MIP thin films in 2009 to investigate conformational changes in $\mathrm{BLG}^{36}$.

\section{Experimental}

\section{Materials and Methods}

SYPRO ${ }^{\circledR}$ orange protein stain $5000 \mathrm{X}, \beta$ - lactoglobulin, N-isopropylacrylamide (NIPAm), Ntertbutylacrylamide (TBAm), Acrylic acid (AAc), Acrylamide (AAm), Ammonium persulphate (APS), N, N, N, N-tetramethylethylenediamine (TEMED) and N,N'Methylenebisacrylamide (BIS) were all purchased from Sigma Aldrich and stock solutions of the monomers and cross linker were prepared fresh and dissolved in $10 \mathrm{mM}$ PBS pH 7.4. PCR vials and lids were purchased from Bio-Rad. $\beta$ - lactoglobulin was dissolved in $10 \mathrm{mM}$ PBS $\mathrm{pH} 7.4$ and made fresh prior to analysis.

All self-assembly screening experiments, MIP-NP characterisation and reverse-cooling binding assays were performed on a Bio-Rad CF96x thermal cycler. The melting profiles of BLG were measured at different concentrations to determine the optimum protein concentration for subsequent self-assembly monomer screening experiments. SYPRO $®$ orange was diluted to $200 \mathrm{X}$ using PBS buffer and $5 \mu 1$ was added together with $45 \mu 1$ of BLG (0 - 1

$\mathrm{mg} \mathrm{ml} \mathrm{m}^{-1}$ ). Using the melting curve analysis, a protein melting profile of each mixture was constructed by measuring the fluorescence signal after every 30 seconds starting at $20{ }^{\circ} \mathrm{C}$ with $0.5{ }^{\circ} \mathrm{C}$ increments after each cycle up to $94{ }^{\circ} \mathrm{C}$. The excitation emission wavelength was set to the FRET mode which is compatible with SYPRO® orange.

\section{Self-assembly screening and reverse binding assay}

All self-assembly monomer screening experiments were performed by preparing $1 \mathrm{ml}$ prepolymerisation mixtures containing $0.2 \mathrm{mg} \mathrm{ml}^{-1}$ protein and (W mol \%, NIPAm), (X mol \%, TBAm), (Y mol \%, AAc), (Z mol \%, AAm) and $2 \%$ mol BIS where the total concentration of monomers and cross linker is $6.5 \mathrm{mM}$. The reaction mixtures were degassed under vacuum for 30 minutes and allowed to equilibrate for 2 hours prior to analysis. MIP-NP characterisation was performed by initiating a duplicate pre-polymerisation mixture with the addition of $2.4 \mu \mathrm{l}$ $10 \%(\mathrm{v} / \mathrm{v})$ TEMED and $8 \mu \mathrm{l}\left(60 \mathrm{mg} \mathrm{ml}^{-1}\right)$ APS. The polymerization was performed at room temperature for 2 hours and subsequently analysed along with the pre-polymerisation mixtures using the same thermal cycling conditions as described for the protein concentration 
optimisation. Non-imprinted polymer nanoparticles (NIP-NPs) were formed using the same method described for the MIP-NPs but without the addition of the protein template. The negative control consisted of the monomers at the same molar ratio as described for the prepolymerisation mixture but in the absence of the protein. Pre-polymerisation mixtures, MIPNPs, NIP-NP and the negative control containing $0.02 \mathrm{mg} \mathrm{ml}^{-1}$ were prepared in the same manner as described previously.

Reverse cooling binding assays were performed by modifying the PCR protocol. Each sample was heated to $60{ }^{\circ} \mathrm{C}$ and the fluorescence signal was measured every 30 seconds at $-0.5{ }^{\circ} \mathrm{C}$ increments to $4{ }^{\circ} \mathrm{C}$.

\section{Synthesis Procedures}

Batches of MIP-NPs were scaled up to $50 \mathrm{ml}$ reactions using the optimised monomer concentrations determined from DSF experiments. The resultant mixtures were then purified using dialysis with a $50 \mathrm{MW}$ cut off membrane and was exchanged in PBS to determine yield. The absence of the protein from the purified MIP-NP was confirmed by taking a $45 \mu 1$ aliquot before and after and measuring the melting profile as described previously. A $10 \mathrm{ml}$ aliquot was then exchanged in water before freeze drying and the yield was recorded. The solution of MIP-NPs was characterised using DLS and TEM. The size distribution and polydispersity index (PDI) were determined on a zeta sizer Nano (Nano-S) from Malvern Instruments. Samples of MIP-NPs were filtered using a $1.2 \mu \mathrm{m}$ diameter syringe filter and sonicated for 30 seconds. Samples were analysed at $25^{\circ} \mathrm{C}$ in $3 \mathrm{~cm}^{3}$ disposable polystyrene cuvettes $(1.1 \mathrm{ml})$.

For TEM experiments, the samples were again filtered using a $1.2 \mu \mathrm{m}$ diameter syringe filter and sonicated for 30 seconds. A $10 \mu 1$ sample was then dried overnight on a copper grid. Images were taken using a Philips CM20 Transmission Electron Microscope.

The $K_{D}$ of each batch of MIP-NPs were measured using surface Plasmon Resonance SPR. 50 $\mu \mathrm{g} \mathrm{m} \mathrm{m}^{-1}$ of $\beta$-lactoglobulin was immobilised onto the sensor surface via an amine coupling protocol. A self-assembly monolayer was formed on the surface of the chip by immersing it into a solution of $5 \mathrm{mM}$ mercaptodecanoic acid for 24 hours. The resultant chip surface was rinsed with water followed by ethanol and dried under nitrogen. The chip was then docked into the instrument and PBS was used as the flow buffer at a flow rate of $5 \mu 1 \mathrm{~min}^{-1}$. A mixture of $0.1 \mathrm{M}$ of NHS and $0.4 \mathrm{M}$ of EDC were mixed together $(1: 1 \mathrm{v} / \mathrm{v})$ and $50 \mu 1$ was injected onto the machine. A $50 \mu \mathrm{l}$ volume of $\beta$-lactoglobulin $\left(50 \mu \mathrm{g} \mathrm{ml}^{-1}\right)$ was injected over the surface of the sensor in $10 \mathrm{mM}$ sodium acetate buffer $\mathrm{pH} 4.5$. The sensor surface was then blocked by 
injecting $50 \mu \mathrm{l}$ of $1 \mathrm{M}$ ethanolamine. Controls of $50 \mu \mathrm{g} \mathrm{ml}^{-1} \mathrm{BSA}$ and LF were immobilised in the same manner as for BLG on the remaining spots. The binding assay was performed by firstly changing the flow rate to $10 \mu 1 \mathrm{~min}^{-1}$ with $10 \mathrm{mM}$ PBS-SDS and injecting $50 \mu 1$, of the MIP-NPs (0.035-36 $\left.\mu \mathrm{g} \mathrm{ml}^{-1}\right)$ over the BLG immobilised surface. NIP-NPs were injected in the same manner as for MIP-NPs to act as the control. The $\mathrm{K}_{\mathrm{D}}$ was calculated from the response of the MIP-NPs towards the immobilised protein at different concentrations of the MIP-NPs using Langmuir 1:1 binding kinetic model. The response of the NIP-NPs was also measured at different concentrations as a reference response. The response from each MIP-NP was normalised by subtracting the response from the NIP-NPs.

The selectivity of the MIP-NPs towards BLG was assessed by injecting $50 \mu 1$ of MIP-NP (0.035-36 $\left.\mu \mathrm{g} \mathrm{ml}^{-1}\right)$ over each spot and measuring the response towards different protein.

\section{Results and Discussion}

Experiments were performed to determine which concentration of protein would give the most stable and reproducible melting profiles. In $10 \mathrm{mM}$ phosphate buffered saline $\mathrm{pH} 7.4$ (PBS), the melting profiles of different concentrations of BLG in PBS buffer showed that concentrations higher than $1 \mathrm{mg} \mathrm{ml}^{-1}$ gave a signal analogous to a saturated fluorescence signal, which was above the working range of the thermal cycler (Fig. 1A). As the concentration of the protein is reduced, a decreasing melting profile peak was observed with an apparent melting point $(\mathrm{Tm})$ of $31.4^{\circ} \mathrm{C}$. The negative control of buffer in the absence of BLG gave a low stable background fluorescence signal with increasing temperature. For subsequent DSF experiments, protein concentrations of $0.2 \mathrm{mg} \mathrm{ml}^{-1}$ were chosen to allow for any observed changes in the melting profile and Tm upon interaction with the monomers.

\section{Screening of self-assembling monomers and MIP-NP characterisation using DSF}

The screening for self-assembly of monomers onto the protein molecule carried out by preparing $1 \mathrm{ml}$ mixtures containing $0.2 \mathrm{mg} \mathrm{ml}^{-1}$ protein in the presence of the monomers $\mathrm{N}$ tertbutylacrylamide (TBAm), N-isopropylacrylamide (NIPAm), Acrylic acid (AAc) and the cross linker N,N'-Methylenebisacrylamide (BIS) at various molar percentages and were referred to as pre-polymerization mixtures. AAc was used to represent a hydrophilic monomer containing a carboxylic group which is expected to form electrostatic, and hydrogen bonding interactions with polar amino groups on the protein. TBAm is hydrophobic monomer owing to its tertiary methyl group and is considered to form hydrophobic interactions with other 
hydrophobic amino groups on the protein. NIPAm is a thermally responsive monomer and acts as an on/off binding switch upon changes in temperature ${ }^{37}$.

MIP-NPs were characterised from $1 \mathrm{ml}$ reactions containing, $0.2 \mathrm{mg} \mathrm{ml}^{-1}$ of protein and 6.5 $\mathrm{mM}$ of the monomers and cross linker at the same molar ratios as described for the prepolymerisation mixture and were subsequently allowed to polymerise with the addition of APS and TEMED. NIP-NPs were also prepared in the same fashion as described for both the prepolymerisation mixture and MIP-NPs but without the protein template. A negative control containing the same molar ratios of monomer as used for the pre-polymerisation mixture, MIPNP and NIP-NP mixtures was also setup to determine whether the monomers had any effect on the fluorescence signal. Samples for analysis were prepared by mixing $5 \mu 1$ of SYPRO ${ }^{\circ}$ orange dye and $45 \mu 1$ aliquots of each sample into strips of $100 \mu 1$ PCR tubes containing optical lids.

The initial composition of monomers used to assess the applicability of DSF was based on those given by Hoshino ${ }^{8}$ and Poma et $a^{14}$ and contained a molar ratio of $53 \%$ NIPAm, $40 \%$ TBAm, $5 \%$ Acrylic acid, and $2 \%$ BIS crosslinker ${ }^{8,38}$. Melting profiles showed distinct differences in profile shape and fluorescence signal between, pre-polymerisation mixture, MIPNPs, NIP-NPs and the negative control (Fig. 1B). The NIP-NPs and negative control gave a low background fluorescence signal as seen for the negative control suggesting that SYPRO ${ }^{\circledR}$ orange requires the presence of the protein for a fluorescence signal to occur. The melting profile of the pre-polymerisation mixture containing protein in the presence of the acrylic monomers showed a slightly lower Tm compared to the native protein at the same concentrations. This suggests that the original acrylic monomer composition tested has destabilising effect on the protein upon binding due to the presence of a higher proportion of hydrophobic monomers compared to hydrophilic monomers. Our initial expectation was that BLG would form more hydrophobic interactions with TBAm and increase the apparent melting point of BLG due to it being a Lipocalin protein ${ }^{39}$. The melting profile observed for BLG MIP-NPs, showed a large initial fluorescence signal which gradually decreased with increasing temperature. This is analogous to the melting profiles seen for partially unfolded proteins. There are three possible explanations for this observation, although they are not mutually exclusive. The first explanation is that the protein unfolds upon polymerisation, and hence causes a change in the recognition shape. The next reason is that hydrophobic pockets are formed between the MIP-NP and protein allowing more dye molecules to bind. The fluorescence signal from the dye is then slowly quenched as water molecules are allowed into 
the binding site as the protein slowly dissociates from the MIP-NP with increasing temperature. The last explanation is that protein: MIP-NP aggregation is occurring upon polymerisation in the absence of any detergent.

In order to access whether DSF could be used as pre-optimisation step through the analysis of protein stability in the presence of the monomers, a number of different monomer protein pre polymerisation mixtures were tested.

Fig. 2A shows the effect of reducing the molar percentage of hydrophobic monomer ligands in the pre polymerisation mixtures. As the molar ratio of TBAm is reduced and the molar ratio of AAc is increased, there is an observed increase in Tm further confirming that hydrophobic acrylic monomers have a destabilising effect on the protein upon binding while the hydrophilic monomer has the opposite effect.

The peak intensity due to the SYPRO ${ }^{\circledR}$ orange also decreased with an increase in AAc monomer composition due to a reduction in hydrophobic interactions between the protein and TBAm monomers and due to competition between the dye and hydrophilic monomers for protein binding. This effect is also observed in Fig 2B where a decrease in NIPAm monomer composition with increasing AAc monomer compositions also resulted in an increase in the $\mathrm{Tm}$ and a decrease in peak intensity from the observed melting profiles.

\section{Investigation of MIP-NP aggregation}

The Melting profiles of the pre-polymerisation mixture containing a monomer composition of 20\% NIPAm, 20\% TBAm, $58 \%$ Acrylic acid, and 2\% BIS (Fig 3, A) gave a higher increase in Tm and decrease in the intensity of the peak signal which suggests a higher protein stability compared to the native protein melting profile (Fig 3, B) while still retaining the thermal responsive properties of the MIP-NPs and was chosen for all subsequent experiments. The same melting profile was observed for all MIP-NPs (Fig 3, C) regardless of the ratio of monomers in the mixtures suggesting that the monomer composition had little impact on the degree of polymerization or protein: MIP-NP aggregation. These results may even suggest that the reaction conditions are a critical parameter in maintaining the native structure of the protein during molecular imprinting rather than increasing the extent of self-assembly of acrylic monomers onto the protein. These results suggest that DSF can be used as a qualitative method to characterize the formation of MIP-NPs and to screen for self-assembly of monomers towards a protein. The melting profile for the NIP-NP (Fig. 3, D) also confirmed that any observed fluorescence signal required the presence of the protein. In order to investigate whether the 
melting profiles observed for the MIP-NPs were due to aggregation and to see what effect detergents have on the protein at low concentrations, we repeated the earlier experiments and included the detergent sodium dodecyl sulphate (SDS) in all mixtures. From the original method, SDS was added in small concentrations to the reaction mixture well below the critical micelle point ${ }^{8}$. The role of SDS in MIP-NPs synthesis is currently unclear from the literature but two possible uses could be as detergent to prevent MIP-NP aggregation upon polymerization or to competitively bind to the protein as a spacer molecule to prevent the encapsulation of the protein. When SDS was added at concentrations greater than $0.2 \mathrm{mg} \mathrm{ml}^{-1}$, protein precipitation was observed further confirming that SDS concentration is a critical factor in MIP-NP synthesis in terms of protein stability and this has been confirmed in the literature ${ }^{40}$.

Melting profiles of the optimised pre-polymerisation mixture, MIP-NPs and NIP-NPs in the presence and absence of $0.02 \mathrm{mg} \mathrm{ml}^{-1}$ SDS were measured (Fig. 4). When compared to the melting profile of the pre-polymerisation mixture containing no SDS (Fig. 4, A), a further shift in melting point and a very small increase in signal from the baseline was observed for the prepolymerisation mixture containing SDS (Fig. 4, B) suggesting that SDS does indeed bind to the protein and also contributes to the protein stability at low concentrations.

When the melting profiles of the MIP-NP reaction in the absence of SDS (Fig. 4, C) is compared to the MIP-NP in the presence of SDS (Fig. 4, D), the former shows a lower initial fluorescence signal which increases slightly with increasing temperature before decreasing after $50^{\circ} \mathrm{C}$. Again the melting profile of the NIP-NPs show only a background fluorescence signal. These results confirm that SDS detergent can assist MIP-NP synthesis by preventing nanoparticle aggregation at low concentrations. SDS can also be said to act as a binding competitor with the monomers and SYPRO ${ }^{\circledR}$ orange dye for binding to the protein which may impede crosslinking of the monomers around the protein and reduce the possibility of encapsulation. These results also demonstrate that there is very little protein encapsulation observed after the polymerization due to the decrease in signal from the MIP-NPs. If encapsulation is observed in the majority of MIP-NPs formed then a higher fluorescence signal should be observed which stays relatively constant with temperature as in theory the protein will be prevented from unfolding regardless of temperature.

\section{Assessment of MIP-NP performance}

To assess the binding affinity and selectivity of the MIP-NPs for $\beta$-lactoglobulin with the optimised monomer ratios, the MIP-NPs were synthesised by scaling up the reaction to $50 \mathrm{ml}$. 
Mixtures containing the protein and monomers were degassed to remove the oxygen in the sample by sonicating under vacuum. The reaction was again initiated using APS and TEMED. The resultant MIP-NPs were purified using dialysis membrane with a 20 KDa MW cut-off and with frequent water changes over 4 days. The removal of the protein was confirmed by measuring the melting profile before and after dialysis (supporting information Fig. S1). The absence of any signal from the MIP-NPs after dialysis confirmed the effective removal of the template. The purified sample was then characterised for size distribution and PDI using DLS. The size of the MIP-NPs was determined to be $194 \pm 3.71 \mathrm{~nm}$ while the PDI was $0.191 \pm 0.038$. The TEM image of the MIP-NPs (Fig. 5) confirms the presence of the MIP-NPs but suggests that the MIP-NPs shrink in size upon drying. . A similar TEM image was obtained for the NIPNP although the particle sizes do differ from the TEM given for the MIP-NP (supporting information Fig S2).

Apparent binding affinities $\left(\mathrm{K}_{\mathrm{D}}\right)$ and the selectivity of BLG MIP-NPs were assessed using an SPR sensor. $\beta$ - lactoglobulin was immobilised on channel 1 using an amine coupling protocol while $\beta$ - lactoferrin (LF) and bovine serum albumin (BSA) were immobilised as the controls on the additional spots. The binding affinity assay was performed by setting the flow rate to $10 \mu 1 \mathrm{~min}^{-1}$ with $10 \mathrm{mM}$ PBS-SDS pH 7.4 and injecting $0.035-36 \mu \mathrm{g} \mathrm{ml}^{-1}$ of the purified MIPNPs over the surface sensor. The concentration of each MIP-NP sample was determined from the weight of a freeze dried sample of MIP-NPs using an equation detailed in the supporting information. The $\mathrm{K}_{\mathrm{D}}$ was determined to be $14.7 \pm 10.6 \mathrm{nM}$ from the response of the MIP-NPs towards the immobilised proteins (Fig. 6A). Responses were normalised by subtracting the NIP-NP signal from the responses given for the MIP-NPs.

The selectivity of the MIP-NPs towards BLG was also assessed using SPR by measuring the response of the MIP-NP at the highest concentration used for the binding assay for the proteins $\beta$ - lactoferrin (LF) and bovine serum album (BSA), both of which are found in milk. The synthesised MIP-NP showed a bigger response towards BLG when compared to LF and BSA demonstrating adequate selectivity (Fig. 6B). The NIP-NP demonstrated a $<10$ RU when injected over the control proteins.

To further investigate the binding of the resultant MIP-NPs towards BLG, a reverse binding assay was setup to determine whether DSF could be potentially used as a qualitative binding method. Again four different mixtures of protein, MIP-NP: protein, NIP-NP and prepolymerisation were prepared and $45 \mu 1$ aliquots were mixed with SYPRO ${ }^{\circledR}$ orange. The 
melting profiles were recorded by heating the samples to $60{ }^{\circ} \mathrm{C}$ and recording the fluorescence at $-0.5{ }^{\circ} \mathrm{C}$ increments (supporting information Fig. S3). At $60{ }^{\circ} \mathrm{C}$ the protein MIP-NP complex is assumed to be fully dissociated due to the presence of NIPAm in the nanoparticle. As the temperature was decreased, the fluorescence signal increased as association between the protein and MIP-NP takes place. Below room temperature the fluorescence signal started to decrease again due to the slow release of the protein. Again the NIP-NPs shows no signal suggesting that the presence of the protein is needed for any detectable signal. These results suggest that DSF can be used to confirm the binding of protein: MIP-NP using the thermally responsive properties of the MIP-NPs.

\section{Conclusions}

In this paper, we have demonstrated for the first time that DSF can be used as a tool for analysing the self-assembly of acrylic monomers towards a protein template and characterisation of acrylic MIP-NPs. The results from this technique suggest that preserving the structure of the protein is critical in achieving good imprinting and the presence of certain acrylic monomers can cause the partial unfolding of protein templates meaning that the resultant MIP-NPs may not bind a protein in its native state. The results also show that the use of the detergent SDS is crucial in precipitation polymerisation and serves to prevent protein: MIP-NP aggregation. It also stabilises the protein template at low concentrations and may play a part in reducing encapsulation of the protein.

DSF was used to demonstrate qualitative binding between the protein and the MIP-NPs. This technique has been demonstrated to be a rapid, and sensitive technique which allows for up to 96 reactions to be screened at the same time, reducing the time and cost needed to develop MIP-NPs for proteins. The technique could be applicable to a wide range of proteins and gives the researcher a powerful tool in the rational design of MIP-NPs. Currently we are looking at using this technique to develop MIP-NPs for other proteins.

\section{Acknowledgements}

The authors would like to thank Innovate UK for partial funding of this work (Project no: 34312-241239).

\section{References}

1 X. L. Song, S. F. Xu, L. X. Chen, Y. Q. Wei and H. Xiong, J. Appl. Polym. Sci., 2014, 131,18 . 
2 Y. Hoshino, H. Koide, T. Urakami, H. Kanazawa, T. Kodama, N. Oku and K. J. Shea, J. Am. Chem. Soc., 2010, 132, 6644-6645.

3 J. Jagur-Grodzinski, Polym. Adv. Technol., 2009, n/a-n/a.

4 L. Li, Y. Lu, Z. Bie, H. Y. Chen and Z. Liu, Angew. Chemie - Int. Ed., 2013, 52, 74517454.

5 D. R. Kryscio and N. A. Peppas, Acta Biomater., 2012, 8, 461-473.

6 E. Verheyen, J. P. Schillemans, M. Van Wijk, M. A. Demeniex, W. E. Hennink and C. F. Van Nostrum, Biomaterials, 2011, 32, 3008-3020.

7 M. J. Whitcombe, I. Chianella, L. Larcombe, S. A. Piletsky, J. Noble, R. Porter and A. Horgan, Chem. Soc. Rev., 2011, 40, 1547-1571.

8 Y. Hoshino, T. Kodama, Y. Okahata and K. J. Shea, J. Am. Chem. Soc., 2008, 130, $15242-15243$.

9 S. H. Lee, Y. Hoshino, A. Randall, Z. Zeng, P. Baldi, R. A. Doong and K. J. Shea, J. Am. Chem. Soc., 2012, 134, 15765-15772.

10 K. Yoshimatsu, B. K. Lesel, Y. Yonamine, J. M. Beierle, Y. Hoshino and K. J. Shea, Angew. Chemie - Int. Ed., 2012, 51, 2405-2408.

11 H. He, G. Fu, Y. Wang, Z. Chai, Y. Jiang and Z. Chen, Biosens. Bioelectron., 2010, 26, $760-765$.

12 H. Chen, J. Kong, D. Yuan and G. Fu, Biosens. Bioelectron., 2014, 53, 5-11.

13 X. Li, B. Zhang, W. Li, X. Lei, X. Fan, L. Tian, H. Zhang and Q. Zhang, Biosens. Bioelectron., 2014, 51, 261-7.

14 A. Poma, A. Guerreiro, S. Caygill, E. Moczko and S. Piletsky, RSC Adv., 2014, 4, 4203-4206.

15 S. Ambrosini, S. Beyazit, K. Haupt and B. Tse Sum Bui, Chem. Commun., 2013, 49, 6746-6748.

16 Z. Altintas, M. Gittens, A. Guerreiro, K.-A. Thompson, J. Walker, S. Piletsky and I. E. Tothill, Anal. Chem., 2015, 87, 6801-6807. 
17 O. Hayden, P. A. Lieberzeit, D. Blaas and F. L. Dickert, Adv. Funct. Mater., 2006, 16, 1269-1278.

18 J. Xu, S. Ambrosini, E. Tamahkar, C. Rossi, K. Haupt and B. Tse Sum Bui, Biomacromolecules, 2016, 17, 345-353.

19 B. Pluhar and B. Mizaikoff, Macromol. Biosci., 2015, 15, 1507-11.

20 L. Cenci, E. Andreetto, A. Vestri, M. Bovi, M. Barozzi, E. Iacob, M. Busato, A. Castagna, D. Girelli and A. M. Bossi, J. Nanobiotechnology, 2015, 13, 51.

21 M. J. Abdin, Z. Altintas and I. E. Tothill, Biosens. Bioelectron., 2015, 67, 177-183.

22 Z. Altintas, B. France, J. O. Ortiz and I. E. Tothill, Sensors Actuators B Chem., 2016, 224, 726-737.

23 G. D. Olsson, K. Niedergall, M. Bach, B. C. G. Karlsson, G. Tovar and I. A. Nicholls, Polym. J., 2015, 47, 827-830.

24 I. A. Nicholls, H. S. Andersson, K. Golker, H. Henschel, B. C. G. Karlsson, G. D. Olsson, A. M. Rosengren, S. Shoravi, S. Suriyanarayanan, J. G. Wiklander and S. Wikman, Anal. Bioanal. Chem., 2011, 400, 1771-86.

25 L. Levi and S. Srebnik, J. Phys. Chem. B, 2010, 114, 107-14.

26 L. Levi and S. Srebnik, J. Phys. Chem. B, 2010, 114, 16744-51.

27 L. Levi and S. Srebnik, J. Phys. Chem. B, 2011, 115, 14469-14474.

28 F. H. Niesen, H. Berglund and M. Vedadi, Nat. Protoc., 2007, 2, 2212-2221.

29 J. K. Kranz and C. Schalk-Hihi, in Methods in Enzymology, ed. C. K. Lawrence, Academic Press, 2011, vol. Volume 493, pp. 277-298.

30 T. H. Steinberg, L. J. Jones, R. P. Haugland and V. L. Singer, Anal. Biochem., 1996, 239, 223-237.

31 E. H. Mashalidis, P. Śledå, S. Lang and C. Abell, Nat. Protoc., 2013, 8, 2309-2324.

32 J. J. Lavinder, S. B. Hari, B. J. Sullivan and T. J. Magliery, J. Am. Chem. Soc., 2009, 131, 3794-3795. 
33 M. Vedadi, F. H. Niesen, A. Allali-Hassani, O. Y. Fedorov, P. J. Finerty Jr, G. A. Wasney, R. Yeung, C. Arrowsmith, L. J. Ball, H. Berglund, R. Hui, B. D. Marsden, P. Nordlund, M. Sundstrom, J. Weigelt and A. M. Edwards, Proc. Natl. Acad. Sci. U. S. A., 2006, 103, 15835-15840.

34 A. I. Alexandrov, M. Mileni, E. Y. T. Chien, M. A. Hanson and R. C. Stevens, Structure, 2008, 16, 351-359.

35 C. Bhattacharjee and K. P. Das, Eur. J. Biochem., 2000, 267, 3957-3964.

36 N. W. Turner, X. Liu, S. A. Piletsky, V. Hlady and D. W. Britt, Biomacromolecules, 2007, 8, 2781-2787.

37 W. Zhang, Z. Mao and C. Gao, J. Colloid Interface Sci., 2014, 434, 122-129.

38 A. Poma, A. Guerreiro, M. J. Whitcombe, E. V Piletska, A. P. F. Turner and S. A. Piletsky, Adv. Funct. Mater., 2013, 23, 2821-2827.

39 F. Roth-Walter, L. F. Pacios, C. Gomez-Casado, G. Hofstetter, G. A. Roth, J. Singer, A. Diaz-Perales and E. Jensen-Jarolim, PLoS One, 2014, 9, e104803.

40 A. K. Bhuyan, Biopolymers, 2010, 93, 186-99. 


\section{SCHEMES}

\section{Scheme 1}

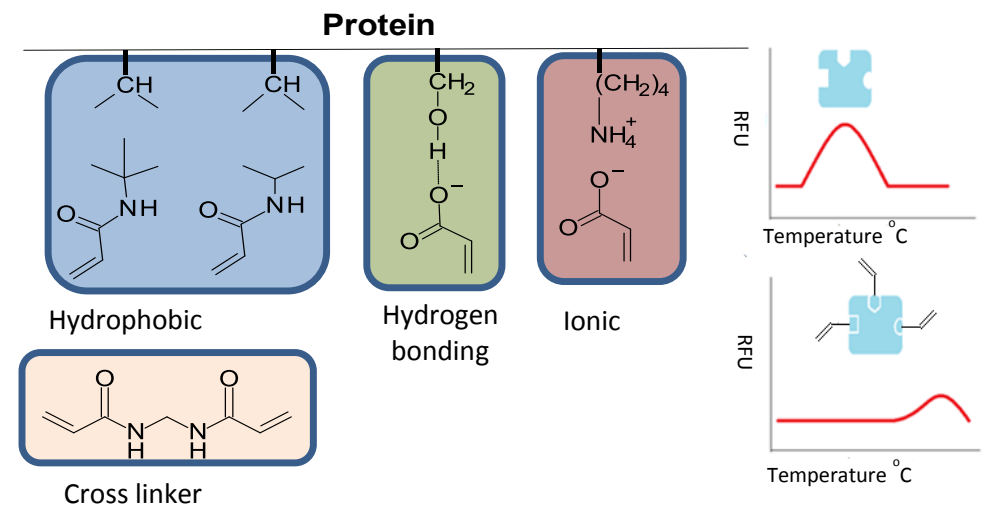

Scheme 1. Melting profiles using DSF in the optimization and characterization of MIP-NPs for a protein in PBS buffer and a protein in the presence of a mixture of acrylic monomer ligands. 
FIGURES

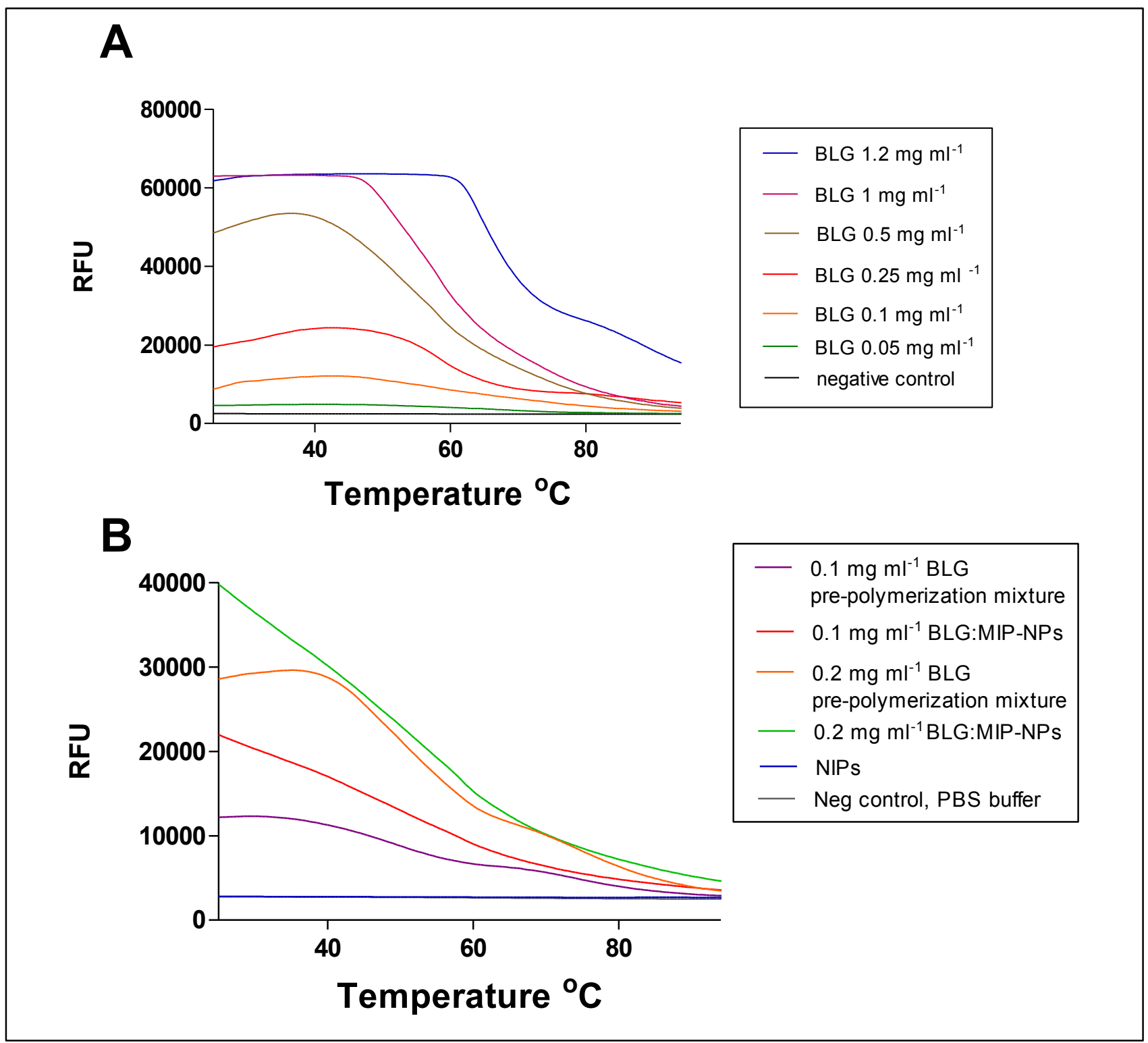

Figure 1. Melting profiles for A BLG $\left(0.05-1.2 \mathrm{mg} \mathrm{ml}^{-1}\right)$ in $10 \mathrm{mM}$ PBS buffer; $\mathbf{B}$ Melting profile for Pre-polymerization mixture, MIP-NPs, NIP-NPs and negative control in the presence of 0.1 and $0.2 \mathrm{mg} \mathrm{ml}^{-1}$. 


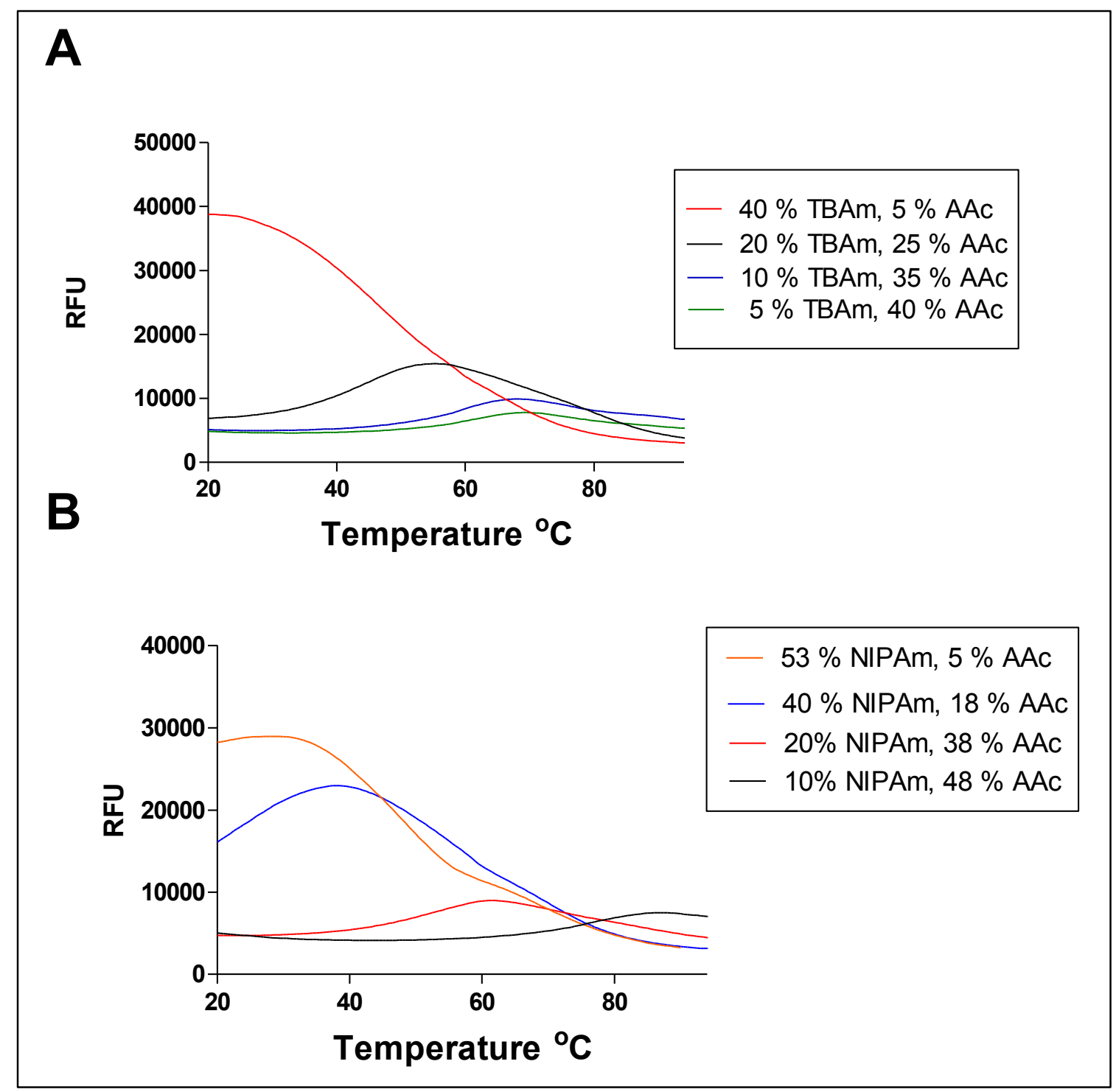

Figure 2. Melting profiles of $0.2 \mathrm{mg} \mathrm{ml}^{-1} \mathrm{BLG}$ pre-polymerization mixtures of $\%$ mole composition: A 53\% NIPAm, X \% TBAm, Y \% Acrylic acid and $2 \%$ BIS (where X $=5-40$ $\%, Y=5-40 \%$ ); $\mathbf{B}$ X \% NIPAm, $40 \%$ TBAm, Y \% AAc and $2 \%$ BIS (where $\mathrm{X}=10-53 \%$, $\mathrm{Y}=5-48 \%$ ). Total Monomer and cross linker concentration $6.5 \mathrm{mM}$. Experiments were performed in Triplicate. 


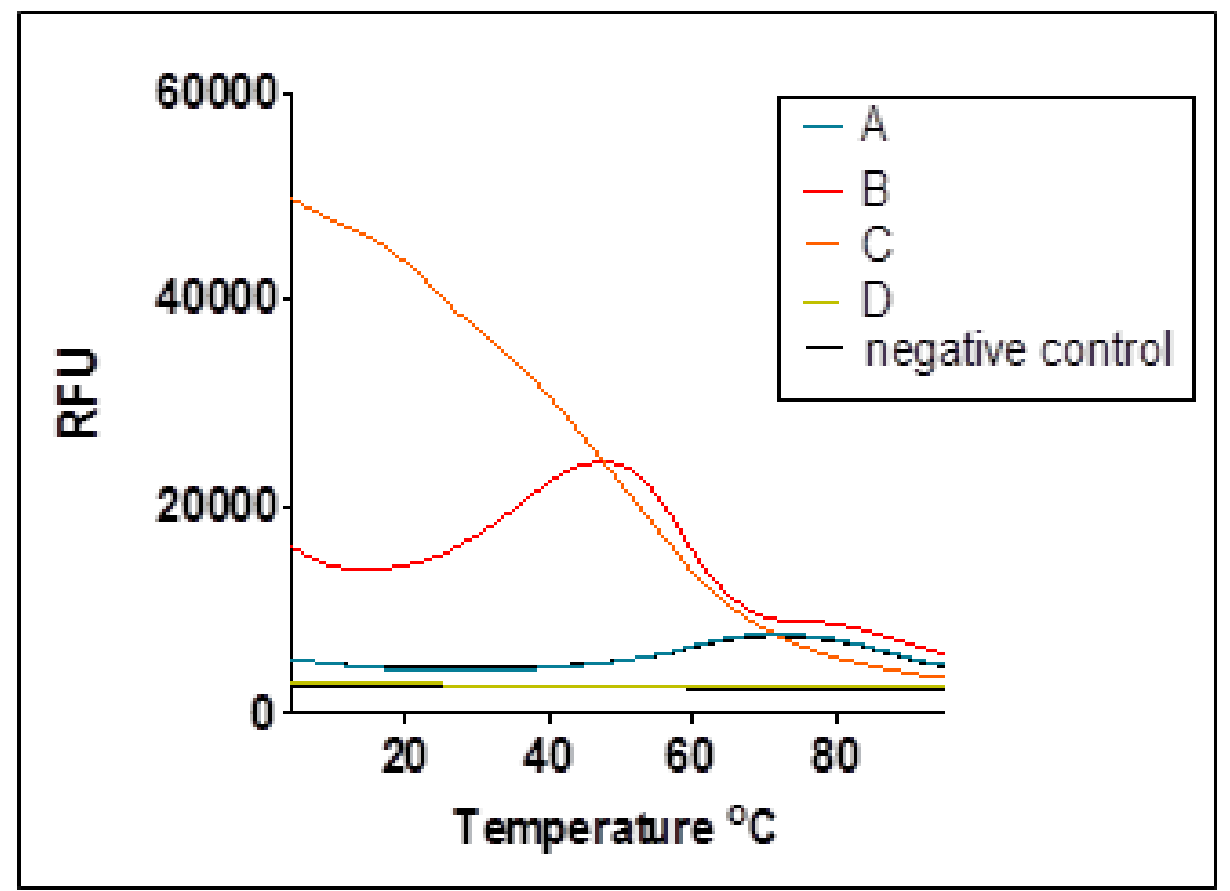

Figure 3. Melting profiles of A $0.2 \mathrm{mg} \mathrm{ml}^{-1} \mathrm{BLG}$ pre-polymerization mixture of composition: 20\% NIPAm, 20\% TBAm, $58 \%$ Acrylic acid, and 2\% BIS; B $0.2 \mathrm{mg} \mathrm{ml}^{-1}$ BLG native protein; C MIP-NP: protein complex and D NIP-NP. The total Monomer and cross linker concentration was $6.5 \mathrm{mM}$ and experiments were performed in Triplicate. 


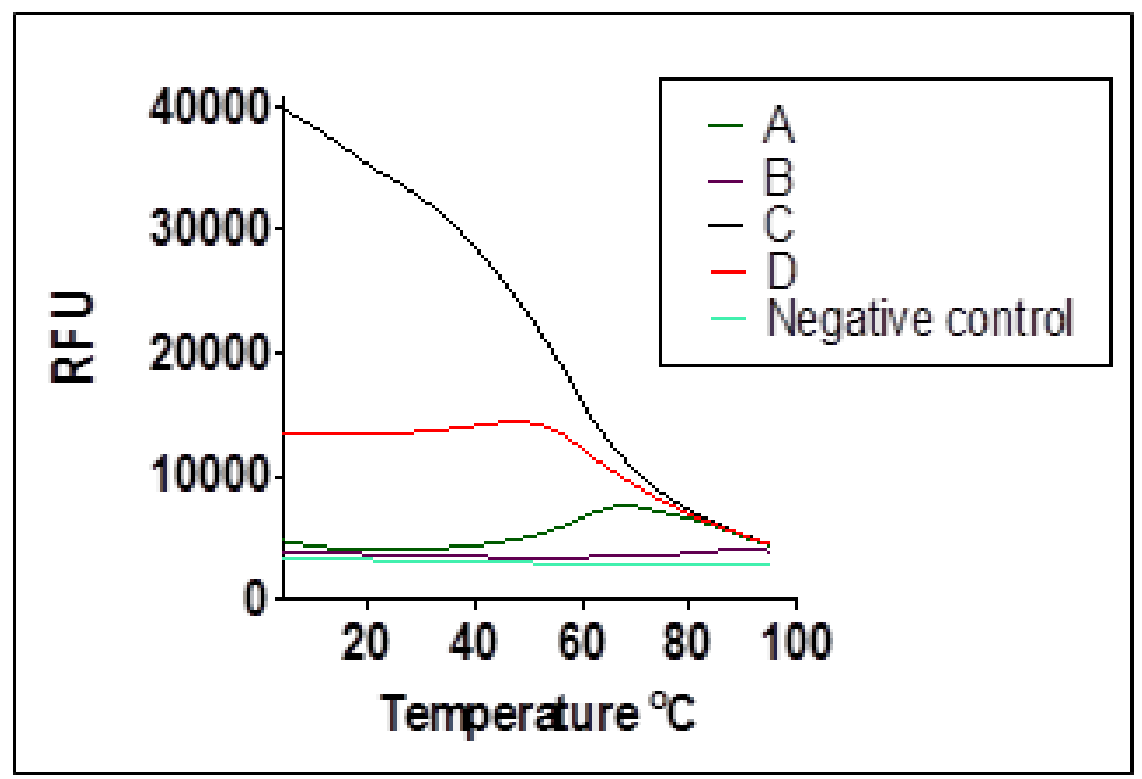

Figure 4. Melting profiles of $0.2 \mathrm{mg} \mathrm{ml}^{-1}$ BLG and the optimized monomer composition: 20 $\%$ NIPAm, $20 \%$ TBAm, $58 \%$ Acrylic acid, and $2 \%$ BIS in the absence of SDS (A) and presence of $0.02 \mathrm{mg} \mathrm{ml}^{-1} \mathrm{SDS}(\mathrm{B})$; MIP-NP: protein complex in the absence (C) and presence (D) of $0.02 \mathrm{mg} \mathrm{ml}^{-1} \mathrm{SDS}$. The total Monomer and cross linker concentration was $6.5 \mathrm{mM}$ and experiments were performed in Triplicate. 


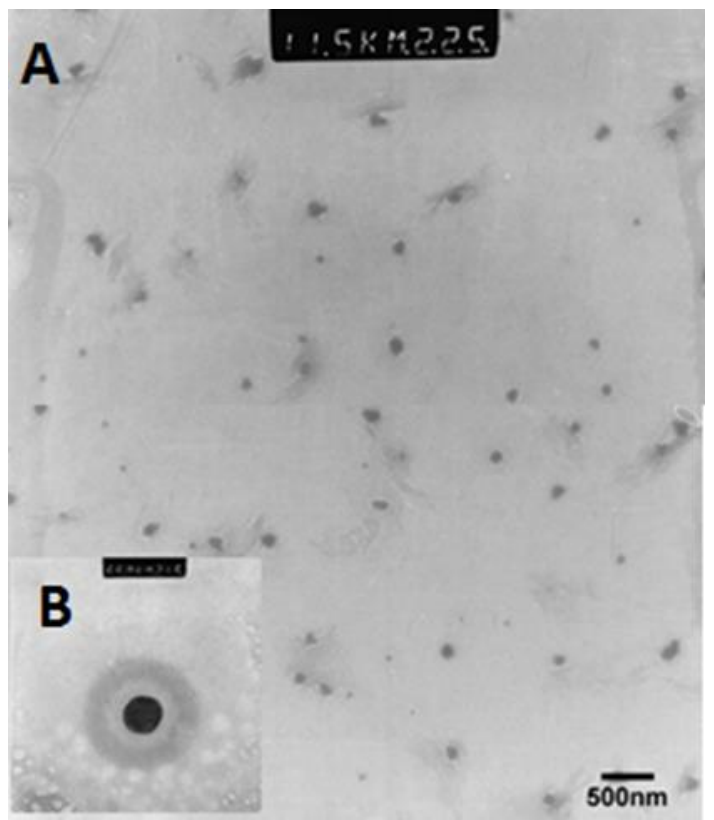

Figure 5. Typical TEM image of MIP-NPs synthesized from the scaled up MIP-NP synthesis. 


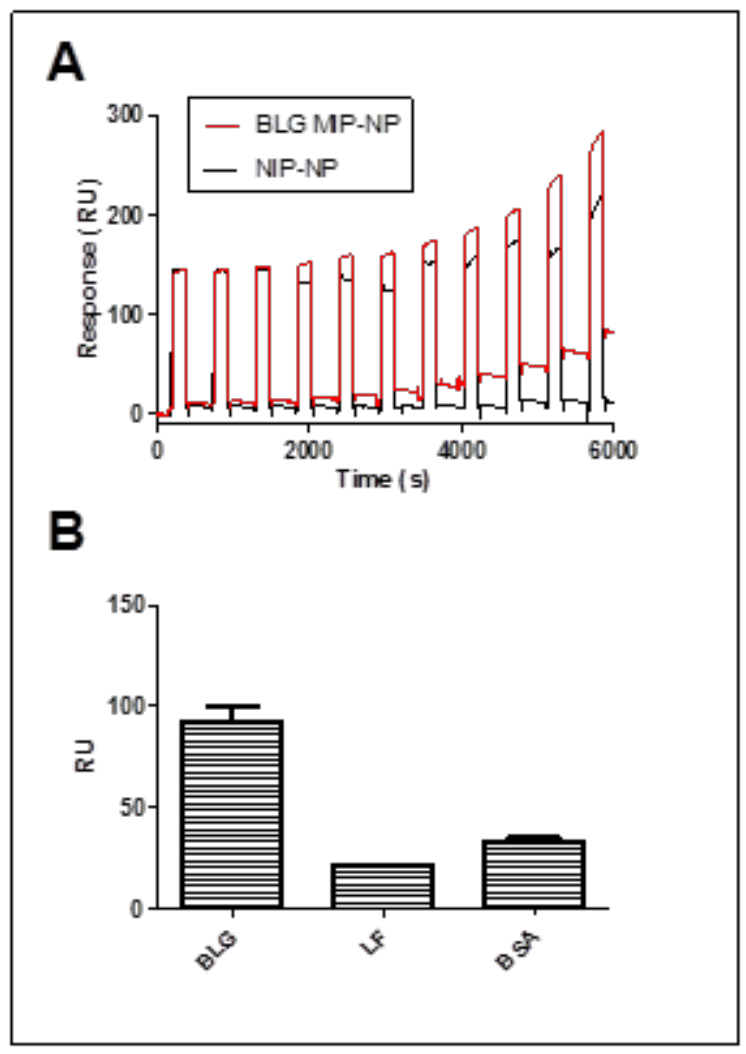

Figure 6. SPR binding affinity Sensorgram showing the response of 0-200 nM BLG MIP-NPs; B Evaluation of MIP-NP selectivity towards bovine serum albumin (BSA), and $\beta$-lactoferrin (LF). 


\section{The use of Differential Scanning Fluorimetry in the Rational Design of Plastic Antibodies for Protein Targets}

Jon Ashley, ${ }^{a}$ Yunus Shukor ${ }^{\mathrm{b}}$ and Ibtisam E. Tothill ${ }^{\mathrm{a}^{*}}$

${ }^{a}$ Cranfield University, College Road, Cranfield, Bedfordshire MK43 OAL, England, UK

${ }^{b}$ Dept. of Biochemistry, Faculty of Biotechnology and Biomolecular Sciences, Universiti Putra Malaysia, 43400 UPM Serdang, Selangor, Malaysia. Corresponding Author; i.tothill@cranfield.ac.uk

\section{Supporting Information}

Determination of the apparent molarities: Apparent Molarities by weighing freeze dried 10 $\mathrm{ml}$ aliquots of purified MIP-NPs and calculated using Equation S1 where $N_{A}$ is Avogadro's constant, $d$ is the hydrodynamic diameter $(\mathrm{nm})$ determined from DLS, $\rho$ is the density of the nanoparticles $\left(\mathrm{g} \mathrm{cm}^{-3}\right)$ and $\mathrm{X}$ is the weight concentration $\left(\mathrm{g} \mathrm{ml}^{-1}\right)$. The density of the nanoparticles is assumed to be $0.08 \mathrm{~g} \mathrm{~cm}^{-3}$.

$$
[\mathrm{NPs}]=\frac{6}{\pi N_{A} d^{3} \rho} X
$$




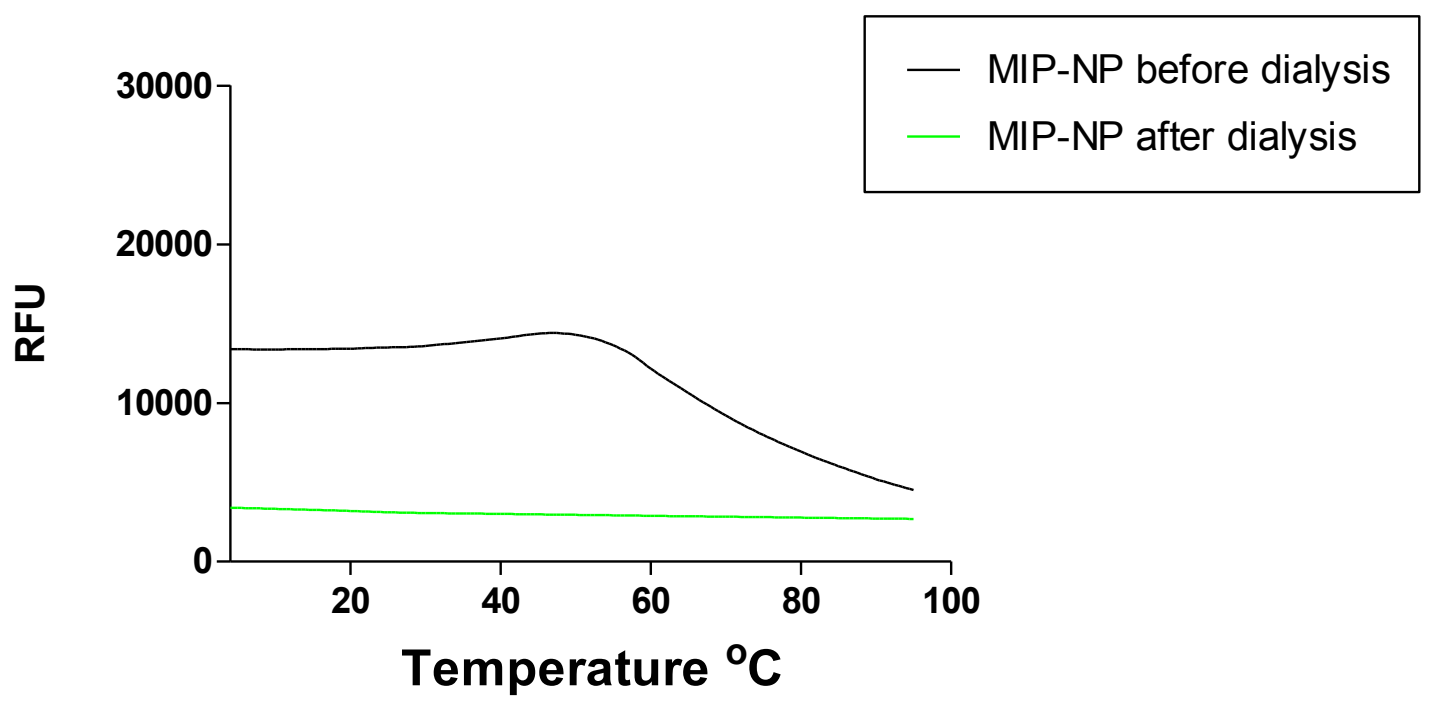

Figure S1. Melting profiles of the scaled up MIP-NP synthesis mixture before and after dialysis.

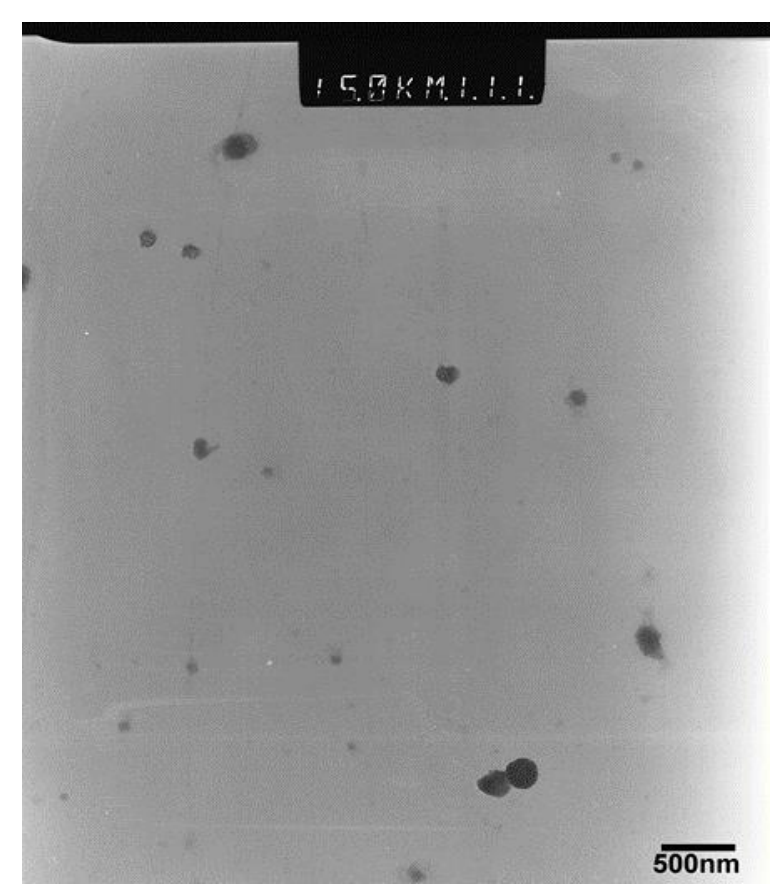

Figure S2. Representative TEM image of NIP-NP 


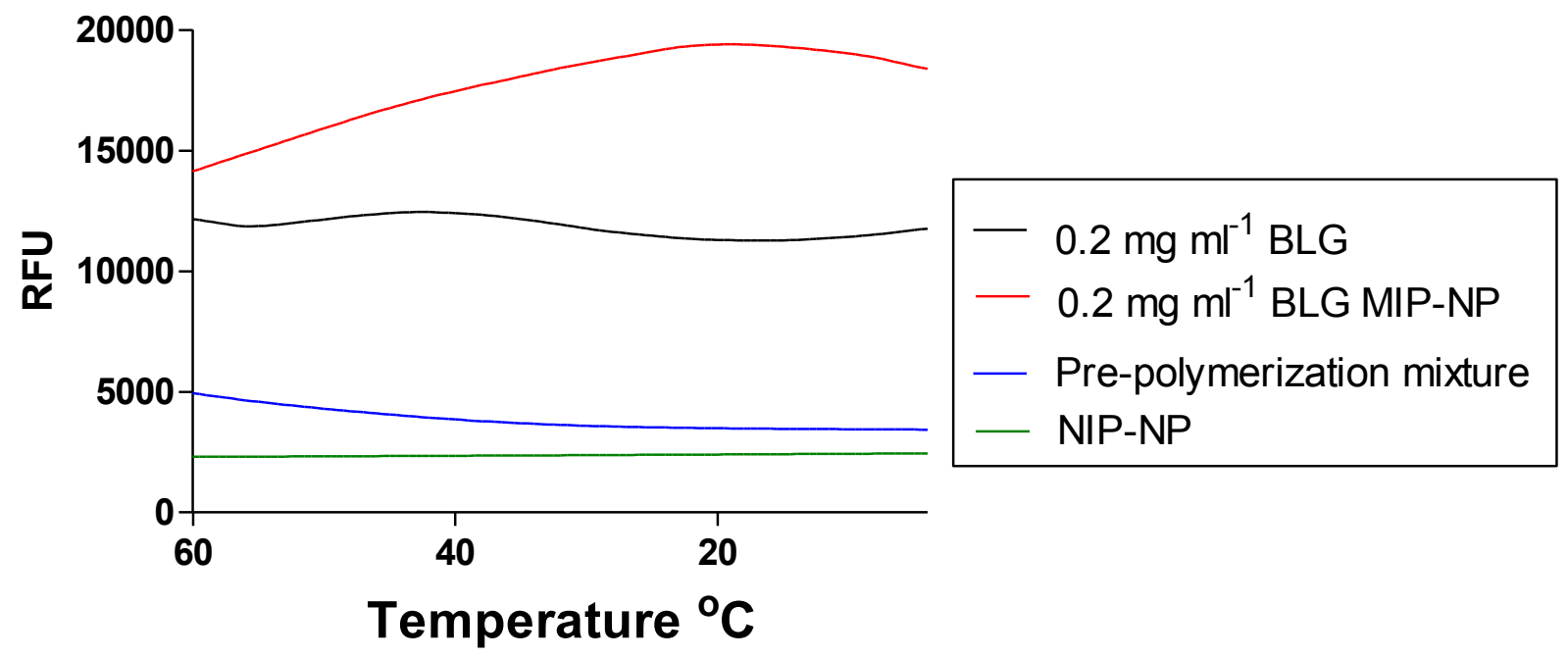

Figure S3. Reverse cooling binding assay melting profile of the native protein, MIP-NP: protein complex, pre-polymerisation mixture and NIP-NP. The fluorescence signal was measured at $0.5^{\circ} \mathrm{C}$ increments every 30 seconds from $60{ }^{\circ} \mathrm{C}$ down to $4{ }^{\circ} \mathrm{C}$. 
2016-10-13

The use of differential scanning

fluorimetry in the rational design of plastic antibodies for protein targets

\section{Ashley, J.}

Royal Society of Chemistry

Ashley J, Shukor Y, Tothill IE, The use of differential scanning fluorimetry in the rational design of plastic antibodies for protein targets, Analyst, Volume 141, Issue 23, 2016, pp. 6463-6470 https://dspace.lib.cranfield.ac.uk/handle/1826/11207 Downloaded from Cranfield Library Services E-Repository 